\title{
A TRADIÇÃO DOS NÃO-HERDEIROS. CONSIDERAÇÕES SOBRE LITERATURA E ENGAJAMENTO A PARTIR DE BERTOLT BRECHT E VIRGINIA WOOLF.
}

\author{
Jordi Carmona HURTADO ${ }^{1}$
}

\section{Resumo}

A finalidade do presente ensaio é dupla. De um lado, trata-se de interrogar a origem da expressão dos "tempos sombrios" na lírica de Brecht, para depois examinar a pertinência como diagnóstico de nosso presente. De outro lado, trata-se de confrontar certa figura brechtiana do poeta engajado com um ensaio de Virginia Woolf, que o tipifica como escritor da torre inclinada. Finalmente, tentamos salientar uma figura insólita e alternativa à do poeta dos tempos sombrios, que também aparece em Woolf, o escritor plebeu. A literatura aparece assim como uma tradição sem herdeiros naturais, que apenas pode ser continuada pelos não-herdeiros.

Palavras chave: Brecht, Woolf, literatura, engajamento.

\section{Abstract}

This essay has a double purpose. On one hand, it consist in a research of the origin of the expression "dark times" in Brecht's lyrics, and in an interrogation of the pertinence of this expression as a diagnosis of our time. On the other hand, it confrounts a certain Brechtian figure of the engaged poet with an essay by Virginia Woolf which typifies him as a writer of the leaning tower. Finally, we try to emphasize an unusual and alternative figure to the poet of the dark times who also appears in Woolf, the plebeian writer. Literature thus appears as a tradition without natural heirs, which can only be continued by nonheirs.

Keywords: Brecht, Woolf, politics, engagement.

\section{Resumen}

La finalidad de este ensayo es doble. En primer lugar, tratamos de interrogar el origen de la expresión "tiempos sombríos" en la lírica brechtiana, para después examinar su pertinencia como diagnóstico de nuestro presente. En segundo lugar, confrontamos cierta figura brechtiana del poeta comprometido con un ensayo de Virginia Woolf que lo tipifica como escritor de la torre inclinada. Finalmente, tratamos de poner en relieve una figura insólita y alternativa a la del poeta de los tiempos sombríos, que también aparece en Woolf, y es la del escritor plebeyo. La literatura, de este modo, aparece como una tradición sin herederos naturales, que solo puede ser proseguida por los no herederos.

Palabras clave: Brecht, Woolf, literatura, compromiso.

\footnotetext{
${ }^{1}$ Universidade Federal do Rio Grande do Norte. E-mail: zoparo@gmail.com 
O senhor Keuner, um dos sósias de Brecht, na sua tentativa de produzir uma transvaluação socialista de todos os valores burgueses, confiava em que um pensamento seria tanto mais valioso quanto menos individual e associado a um nome próprio, e quanto mais anônimo e citável (BRECHT, 2006, p. 84). Seja qual for nossa valoração desse prognóstico, é preciso reconhecer que ao menos isso foi certo para ele mesmo, e hoje em dia qualquer discussão política bebe sua pequena dose de lírica em Brecht ou em fontes que supostamente nascem de Brecht. Eis o que acontece, entre outras, com a expressão de "tempos sombrios", retomada mais tarde por Hannah Arendt em uma coletânea de ensaios biográficos, e que tende a adquirir a função de resumir em um diagnóstico que também funciona como palavra de ordem a tonalidade fundamental do nosso presente, que condicionaria nossos projetos, nossas esperanças e nossa capacidade de ação, seja de confrontação direta com o que é sombrio nesses tempos sombrios, seja de desenvolvimento de práticas de resistência às novas trevas. A finalidade das considerações que seguem é examinar não apenas os remédios possíveis, mas a pertinência mesma desse diagnóstico.

\section{OS TEMPOS SOMBRIOS}

A temática dos tempos sombrios se origina, com efeito, na produção lírica brechtiana. É o célebre poema Aos que vão nascer (An die Nachgeborenen) que o declara, desde seu primeiro verso: "Realmente, eu vivo em tempos sombrios!"2 (BRECHT, 2000, p. 212). Eles são descritos no poema como os tempos da desordem, da exploração, da fome, da criminalidade: é a época do capitalismo e das guerras de classe. A experiência do poeta é dominada, nessa situação, pela má consciência, a consciência de estar faltando a sua vocação. Essa vocação nem sequer é a vocação poética especializada, mas a antiga e mais fundamental vocação de todo homem a uma vida boa e à sabedoria. A condição mais básica da vida boa é a espontaneidade; mas nesses tempos, toda ingenuidade é banida. Nos tempos sombrios, cada ato humano espontâneo resulta imediatamente carregado de culpabilidade: a despreocupação se manifesta como

\footnotetext{
${ }^{2}$ Mesmo se nos apoiamos na tradução de Paulo César de Souza da edição citada, muitas vezes a modificamos para nos aproximarmos do original alemão.

Revista do Instituto Histórico e Geográfico do Pará (IHGP), (ISSN: 2359-0831 - online), Belém, v. 04, n. 02, p. 102-124, jul./dez. 2017.
} 
insensibilidade, o riso como ignorância, e mesmo "Falar de árvores é quase um crime / Pois implica silenciar sobre tantas barbaridades" (BRECHT, 2000, p. 212).

A origem do sentimento de culpabilidade é uma espécie de hipersensibilidade da consciência social. No poema de Brecht não há nada que escape ao olhar dessa consciência, que apenas enxerga o indivíduo através da mediação da coletividade, e que impede qualquer desfrute imediato dos atos humanos mais simples: "Mas como posso comer e beber, se / Tiro o que como ao que tem fome / E meu copo d'água falta ao que tem sede?" (BRECHT, 2000, p. 212). Ainda assim, o personagem principal do poema, que é o poeta mesmo, o "pobre Bertolt Brecht"3, come e bebe: mas come e bebe sem prazer e sem desenvolver nenhuma virtude nessas ações. Tudo o que não tem significação social, o "cuidado de si” estoico, o amor, a contemplação da natureza, ou é declarado inatingível, ou é praticado descuidadamente e sem paciência, o que finalmente resulta no mesmo.

A única virtude que é reivindicada pelo poeta dos tempos sombrios é a própria revolta, a esperança que talvez "Os que mandam / Estariam melhor sem mim" (BRECHT, 2000, p. 213). Ora, não há nada de épico nesse pequeno orgulho do poeta que se revolta. Pois nos tempos sombrios as forças são mínimas, a meta distante, a injustiça é bem maior do que pode mudar qualquer revolta. O poeta-homem revoltado também não se apresenta como um modelo de conduta, mas expõe suas contradições: as contradições do poeta que já não é mais poeta, que não é mais do que um homem qualquer, que se revolta com aqueles que se revoltam. "Também o ódio à baixeza / Deforma as feições. / Também a ira pela injustiça / Torna a voz rouca. Ah, e nós / Que queríamos preparar o chão para a amizade / Não pudemos nós mesmos ser amigos" (BRECHT, 2000, p. 214).

Numa primeira aproximação, o poema aparece como uma justificação dessa existência um pouco descuidada e confusa, por causa dos "tempos sombrios" em que o poeta revoltado teve de fazer sua vida: uma petição de indulgência dirigida ao leitor futuro. Mas esse leitor futuro não é simplesmente um representante qualquer da posteridade. Os que "ainda não nasceram" a que se refere o título são os homens novos, os homens da perfeita sociedade comunista em que "O homem é o companheiro do

\footnotetext{
${ }^{3}$ É o título de outro poema de Brecht, "Do pobre B. B.”, que Hannah Arendt comenta no seu ensaio sobre Brecht pertencente à coletânea Homens em tempos sombrios, que citamos mais adiante. 
homem" (BRECHT, 2000, p. 214). Esse tema quase pastoral do companheirismo, ou da ajuda mútua, ou mesmo do serviço do povo - Brecht usa a expressão Helfer, que quer dizer ajuda, serviço, assistência, mais do que camaradaria, o que se ajusta bastante com sua própria concepção do socialismo ${ }^{4}$ - atua no poema como um elemento de contraste no que diz respeito ao tom dominante, o dos tempos sombrios. Mas também separa dois tipos de humanidade. O poeta ainda é um homem fraco, contraditório, pertencente ao velho mundo: é alguém que declara poder divisar uma meta que ao menos para ele é inatingível.

É difícil saber, quando se trata de um escritor tão político e tão retórico (ou tão dialético) quanto Brecht, cuja produção é dominada pela ironia e a duplicidade, se ele acreditava de algum modo no final dos tempos sombrios e o surgimento desses homens novos. Em qualquer caso, apenas esses novos homens, que são os leitores ideais do poema, nesse novo tempo já não mais sombrio mas transparente, poderiam pensar na existência do pobre B. B. com indulgência. Nós, evidentemente, que não fazemos parte deles, que somos contemporâneos desses "tempos sombrios", e que em certo modo também somos homens revoltados, não poderíamos fazê-lo.

Em uma segunda aproximação, no entanto, que parte justamente dessa posição de contemporaneidade, o poema aparece como uma crítica velada desse mesmo dispositivo que justifica a desatenção ao presente pelo sonho de um futuro ideal. Também como uma autocrítica da posse do poeta em homem revoltado e em parceiro dos oprimidos da terra. E uma autocrítica, enfim, do poeta marxista, do poeta “engajado". Em outro poema de temática semelhante, Mau tempo para a poesia, Brecht continua com seu autorretrato inacabável, sempre no mesmo estilo claro e didático: "Em mim lutam / O entusiasmo pela macieira que floresce / $\mathrm{E}$ o horror pelos discursos do pintor 5 . / Mas apenas o segundo / Me conduz à escrivaninha" (BRECHT, 2000, p. 226). Ora, o problema é que esse horror que é o afeto fundamental que motiva a escrita nos tempos sombrios, junto com outras paixões próximas (o ódio, a ira) também deforma as feições, também torna a voz rouca. E mais fundamentalmente, esse mesmo pathos da revolta é o que torna impossível a meta mesma da revolta, a amizade entre os homens.

\footnotetext{
${ }^{4}$ Eis a história "Duas cidades": "O Sr. K. preferia a cidade B à cidade A. 'Na cidade A', disse ele, 'as pessoas gostam de mim; mas na cidade $\mathrm{B}$ foram amáveis comigo. Na cidade $\mathrm{A}$ colocaram-se à minha disposição; mas na cidade $\mathrm{B}$ necessitaram de mim. Na cidade $\mathrm{A}$ me convidaram à mesa, mas na cidade $\mathrm{B}$ me convidaram à cozinha." (BRECHT, 2006, p. 44).

${ }^{5}$ Evidentemente, se trata do medíocre pintor de paisagens Adolf Hitler.

Revista do Instituto Histórico e Geográfico do Pará (IHGP), (ISSN: 2359-0831 - online), Belém, v. 04, n. 02, p. 102-124, jul./dez. 2017.
} 
Os meios que deveriam conduzir ao fim não deixam de desviar à gente desse mesmo fim. Pois como é possível que aquele que se ocupa descuidadamente do amor possa contribuir de qualquer modo a construir um tipo de sociedade entre os homens cuja base seja a amizade? Com certeza, não é ele, o pobre B. B., quem vai fazer, mas os que ainda não nasceram.

Os tempos sombrios são também aqueles que anunciam a grande catástrofe final, que no poema é representada com a figura clássica do dilúvio que afogará o velho mundo, do qual surgirá uma humanidade completamente renovada. Como temos indicado, há muitas razões para acreditar que o próprio Brecht não partilhava dessa fé; em qualquer caso, não parece muito razoável, em geral, acreditar em profecias. Mas se não acreditamos na catástrofe final nem na chegada do novo homem, se não fazemos confiança a um futuro ideal que poderia justificar nosso presente feito de impaciência e desatenção, algo deveria mudar também em nossa concepção da temporalidade, em nossa percepção do que é sombrio nos tempos sombrios.

\section{SOMBRAS E TORRES}

O que é sombrio nos tempos sombrios refere-se principalmente à obscuridade ou ao obscurecimento da esfera pública: o que nela deveria ser uma luz que dá um foco especial ao que há de mais virtuoso na existência humana e o coloca no centro da vida social como um modelo, ou o que nela deveria tornar mais claros os aspetos obscuros da vida privada, segundo os ideais do iluminismo, é justamente o que esmaga qualquer manifestação dessa existência, distorcendo a natureza e a carregando de culpabilidade. Como diria Hannah Arendt, a falta de liberdade política na esfera pública impede também que floresça na sombra qualquer autêntica liberdade em relação à política ${ }^{6}$. Essa esfera da liberdade da política é a que tradicionalmente habitaram tanto o poeta que celebra a vida segundo a natureza quanto o sábio estoico, que a habita caladamente. Com certeza, em Brecht, esses ideais de uma vida segundo a natureza são vivenciados como algo irremediavelmente passado, objeto de uma nostalgia tingida quase por completo de ironia. E o novo ideal de uma sabedoria da vida social apenas poderia ser

\footnotetext{
6 “A história conhece muitos períodos de tempos sombrios, em que o âmbito público se obscureceu e o mundo se tornou tão dúbio que as pessoas deixaram de pedir qualquer coisa à política além de que mostre a devida consideração pelos seus interesses vitais e liberdade pessoal..." (ARENDT, 2008, p. 14).

Revista do Instituto Histórico e Geográfico do Pará (IHGP), (ISSN: 2359-0831 - online), Belém, v. 04, n. 02, p. 102-124, jul./dez. 2017.
} 
desenvolvido por uns homens que ainda não existem ${ }^{7}$. Mas o poeta dos tempos sombrios, cuja existência em revolta se situa entre uma antiga natureza natural perdida e uma nova natureza social inatingível, cede ao destino desses tempos. Ele se revolta contra os tempos sombrios, mas o faz à maneira dos tempos sombrios: daí que sua revolta seja tão insatisfatória e sem esperança, que ela não faça mais do que aprofundar na tonalidade sombria dos tempos sombrios, para apenas achar uma escapatória mágica, encantatória.

Mas a questão para nós - se não aceitamos a saída brechtiana, se com certeza não somos os homens novos, mas uns homens tão fracos e contraditórios como o pobre B. B. -, é se é possível não ceder ao destino desses tempos. A questão é se é possível, e como seria possível, não ceder ao pathos da revolta e as paixões que o animam (horror, ódio, ira, por mais justificadas e "naturais" que elas pareçam), e ainda assim se opor aos tempos obscuros. E se opor de uma maneira prática, real: fazendo, ao menos, com que sejam menos obscuros, ou com que, como diria Heidegger, a luz pública não obscureça tudo $^{8}$. Para isso, talvez seja preciso colocar em questão o tipo de impulsos que nos conduzem à escrivaninha. E talvez também seja preciso repensar se nossas impaciências e nossa desatenção à inocência, à natureza, ao amor e à espontaneidade humana são realmente necessárias, um destino da vida humana nos tempos sombrios. Se Hannah Arendt tem razão, e a falta de liberdade política também implique a impossibilidade de uma liberdade em relação à política, o fato de não se submeter ao destino do tempo, nem sequer nos termos da simples descrição, talvez seja uma maneira mais adequada de lhe resistir que se revoltar contra ele, ainda que aceitando o caráter sombrio. E talvez, justamente, tudo isso implique uma figura poética para os tempos sombrios que não é mais a que representa Brecht; mesmo se todas essas questões, evidentemente, são as que coloca o poema mesmo de Brecht. Mas mesmo se no próprio Brecht podemos encontrar elementos contrários ou que balançam esse pathos geral - especialmente, mais uma vez, na figura mais serena e estoica do senhor Keuner -, não vamos encontrar as respostas em Brecht.

\footnotetext{
${ }^{7}$ Ao menos é assim na poesia lírica de Brecht. Mas nas Histórias do senhor Keuner, que já temos citado, aparece a possibilidade de uma espécie de um novo estoicismo socialista, um estoicismo adaptado ao longo período de eclosão e maturação da natureza social do homem, através das guerras de classe.

${ }^{8}$ Citado por Arendt: "Das Licht der Öffentlichkeit verdunkelt alles" (ARENDT, 2008, p. 6). 
No entanto, há um ensaio de Virginia Woolf, A torre inclinada, que é muito significativo, enquanto a essa questão do papel da poesia ou da literatura nos "tempos sombrios". Ele articula uma concepção das sequencias históricas semelhante à de Brecht, mas o discurso se desenvolve em um nível de consciência maior, que inclui e tipifica a figura do poeta como homem revoltado. Também efetua um deslocamento na imagem do presente do "tempo sombrio", nessa metáfora que é no fundo completamente iluminista da nova idade das trevas, e que é partilhada tanto na versão marxista de Brecht do capitalismo como pré-história da humanidade socializada, quanto na versão mais "liberal" ou libertária de Hannah Arendt como idade da crise da esfera pública.

Ao invés do eterno combate da luz contra as trevas, a imagem que constrói Woolf refere-se às torres de certa cultura aristocrática que sempre se elevaram por cima da existência da maior parte da população; e de como essas torres, a partir de determinado momento, começaram a se inclinar inelutavelmente. Ela pensa a história e o destino da literatura inglesa, mas seus esquemas de pensamento são universais.

A imagem da torre, da "torre de marfim", é bem conhecida: mas Virginia Woolf a leva muito além da simples temática de denúncia vazia do elitismo. Os escritores ingleses durante o século XIX, escreve Woolf, e até o começo da primeira guerra mundial, habitaram de maneira estável e tranquila em uma ou outra dessas torres, que não eram exatamente de marfim, mas de estuque e ouro. "Todos foram criados, acima do comum do povo, numa torre de estuque - no que toca a seu nascimento na classe alta; e de ouro - no que toca à sua educação dispendiosa" (WOOLF, 2014, p. 438). Para eles essa posição acomodada era uma situação quase natural, que não era interrogada. Não se interessavam pela política, que estava completamente ausente nas suas discussões, mas pela "busca da verdade, as emoções estéticas e as relações pessoais" (WOOLF, 2014, 437). Sua educação estava feita de leituras, em línguas modernas e clássicas. Eles escreviam, mas não tinham pressa de publicar. E viajavam. Durante três ou quatro anhos se expunham "ao sol em Oxford e Cambridge" (WOOLF, 2014, p. 444), e depois conseguiam algum emprego folgado e com tempo livre, por exemplo como professores nessas mesmas universidades, que lhes permitia continuar com seu cultivo das letras. 
Eis a imagem de certa tradição aristocrata da cultura inglesa e de sua tranquila reprodução, que fez nascer quase toda a grande literatura inglesa. Ora, como mostra Virginia Woolf, essa espécie de educação aristocrática, de cria e reprodução de uma pequena classe de homens cuja existência sempre pairara por cima do comum do povo, tem uma relação muito estreita com a educação literária mesma. Pois a arte da escrita, como qualquer outra arte, também precisa ser ensinada. Ora, a formação do escritor é bastante peculiar, porque não é específica: é o que Woolf chama de uma "formação indefinida" (WOOLF, 2014, p. 440). "Ler, ouvir, conversar, viajar, distrair-se - muitas coisas diferentes, ao que parece, se misturam de vez." (WOOLF, 2014, p. 439). Daí que o ócio seja o ambiente adequado tanto para a formação de um escritor quanto para a reprodução de uma aristocracia.

\section{LITERATURA E INCONSCIÊNCIA}

Os escritores ingleses se educavam desse modo como "herdeiros inconscientes de uma grande tradição":

Ponha uma página de sua escrita sob uma lente de aumento e você verá, muito ao longe na distância, os gregos, os romanos; bem mais perto, os elisabetanos; mais perto ainda, Dryden, Swift, Voltaire, Jane Austen, Dickens, Henry James. (WOOLF, 2014, p. 441)

Mas justamente, o importante na demonstração de Woolf é a questão da inconsciência: como se a herança, a verdadeira herança humana, apenas puder ser inconsciente. Essa inconsciência aparece, aliás, em Woolf, não como um estágio mais imediato da vida do espírito, senão mais mediato: a inconsciência, o devir-inconsciente aparece como uma sorte e uma tarefa. Esses escritores conseguiram não ser conscientes da torre de estuque e ouro na qual se elevava sua existência: eis a origem de sua grandeza. Para eles, mais uma vez, a perspectiva da sua existência privilegiada, a visão desde a torre, era natural; mas para nós, diz Woolf, que temos visto essa torre inclinar dramaticamente, o não é mais, e por isso podemos analisa-la. A torre inclinada determina um certo ângulo de visão da vida humana. Entender o mundo da literatura desses escritores da torre de estucou e ouro significa enxergar o mundo desde esse ângulo de visão: significa compreender o mundo deles, ou seja, ver o mundo com seus olhos. Eis o propósito de Woolf no ensaio. 
Quando estamos instalados, de uma maneira tão estável que parece natural, em uma torre de riqueza, cultura e ociosidade, o primeiro fato que se apresenta é que podemos ver ao longe. Essa visão longínqua não se refere apenas ao espaço, mas também ao tempo, a épocas distantes, ao passado e ao futuro: o olhar pode percorrer com tranquilidade e sem impedimento as diferentes dimensões da vida humana. Ora, essa vida humana aparece desde a torre com uma configuração específica: uma “paisagem retalhada em campos à parte” (WOOLF, 2014, p. 433-434). Há diferentes classes ou diferentes estamentos, cada um com seus próprios costumes, tradições, etc. Ele vê uma sociedade dividida em cercados, mas essa divisão lhe parece tão natural que o escritor simplesmente a assimila, a aceita por completo: pois para escrever precisa devir inconsciente das cercas. Por isso as conversações versavam sobre metafísica, poesia ou relações pessoais, e a política nunca entrava nelas.

Isso não quer dizer que o tempo dessa literatura da torre for um tempo claro de paz e prosperidade. Pois apenas era assim desde o ângulo de visão da torre: como lembra Woolf, a Inglaterra nunca deixou de estar envolvida em alguma guerra durante todo o século XIX. Só que a guerra aparecia ao longe como mais um elemento "natural" da paisagem, que não a perturbava mais do que a pobreza de certas classes. A questão essencial aqui, justamente, é a inconsciência das cercas e das guerras, como algo que está longe da própria existência, que não lhe diz respeito. Ora, o fato de ser inconsciente das cercas também permite atravessá-las, sem perturbação, com o olhar. A literatura da torre de estuque e ouro não é uma literatura que nasça da revolta, mas da mais completa submissão à "realidade" e da aceitação do mundo como ele é, mesmo se na verdade trata-se de uma pequena parcela do mundo.

Nós, como diz Woolf, já não podemos mais ignorar a existência das cercas que dividem as classes, mas também não as guerras, que já não estão mais longe, mas que chamam às nossas portas, mesmo se é pelos meios de comunicação. Mas seria um erro e uma presunção sem fundamento deduzir que então, como somos mais conscientes, vamos criar automaticamente uma literatura superior, ou desde uma perspectiva que capte melhor a vida humana. Para esses escritores da torre, "essa inconsciência foi uma imensa vantagem" (WOOLF, 2014, p. 435). Pois a inconsciência é a condição de qualquer literatura e devir inconsciente é a tarefa de qualquer escritor, como podemos concluir do modo em que Woolf descreve o processo da escrita: 
Depois de um dia duro de trabalho, em que dá voltas e mais voltas, vendo tudo, sentindo tudo o que puder, tomando notas inumeráveis no próprio livro da mente, o escritor se torna - caso o consiga - inconsciente. Seu subconsciente trabalha em alta velocidade, de fato, enquanto a consciência cochila. Feita então uma pausa, o véu se ergue; e eis que a coisa - a coisa sobre a qual ele deseja escrever - surge simplificada e serena. (WOOLF, 2014, p. 435)

A verdadeira escrita é então uma atividade inconsciente: "o escritor tem de se tornar inconsciente antes de ser capaz de criar” (WOOLF, 2014, p. 436). Só quando sua consciência cochila ele se torna capaz de criar, ou seja, de olhar para a vida humana como ela é, com suas mudanças, com sua pluralidade, por baixo das representações e opiniões que nos fazemos dela; também nesse momento o escritor conecta com a grande tradição de contemplação da vida humana que é a literatura. Há algo de impessoal, de coletivo, de não voluntário, que se exprime na escrita, e que é sua verdadeira potência independentemente dos projetos e desejos conscientes do autor. Daí que a literatura inglesa do século XIX tenha sido capaz de criar tantos personagens que não são tipos sociais ou estadísticos, mas indivíduos vivos. Do mesmo modo que cada autor era ele mesmo um indivíduo em uma mundo habitado por indivíduos e não por tendências. A literatura, como a vida mesma, apenas é capaz de existir e se desenvolver em um nível “molecular”, como diria Deleuze (DELEUZE, 1997, p. 11 e sq.), e para isso é preciso que o véu de Maia da consciência desapareça.

\section{A LITERATURA DA TORRE INCLINADA}

A grandeza dessa cultura literária da torre de estuque e ouro provem do fato que ela garantia ao escritor uma tranquilidade e estabilidade nas relações humanas que favorecia a tarefa de devir inconsciente. Mas houve um momento em que essa torre começou a inclinar: as mudanças sociais, o tempo da história e das revoluções não podiam ser mais ignoradas. A ordem social deixou de parecer natural, mas assentada em uma história de injustiças e exploração. A política começou a aparecer nas conversar dos escritores: eles se "politizaram", se organizaram em tendências. Também se tornaram mais conscientes que seus antecessores: o que para Tackeray ou Dickens era uma visão literária da vida humana inteira lhes apareceu como uma pequena parcela dessa vida, que deixava fora a maior parte. Não podiam deixar de enxergar as cercas; não estavam mais satisfeitos morando na torre, nem com sua educação dispendiosa nem 
com sua condição aristocrata de herdeiros de uma grande tradição. Tudo o que eles queriam era mudar com o mundo, nesse tempo em que todo o mundo mudava. Queriam partilhar da vida dos que viviam no solo comum; sua única ambição foi a de ser homens entre os homens, abandonar essa existência em uma torre que se elevava por cima do comum.

Ora, insiste Woolf, essas transformações tiveram algo de necessário, e é preciso entendê-las desse modo. Há algo que diz respeito aos tempos históricos, que o escritor não pode mais ignorar, como no poema de Brecht: algo de destino. São justamente os escritores mais sensíveis e mais talentosos que não aguentaram a antiga situação e começaram a abrir as janelas da torre para que entrasse o vento da política. Mas eles também não podiam simplesmente descer da torre para o chão: "é a morte de um escritor jogar fora seu capital; ser forçado a ganhar a vida numa fábrica ou dentro de uma mina." (WOOLF, 2014, p. 446) Daí que a geração que nasceu para a literatura com a guerra de 1914, seja nomeada por Woolf como a dos escritores da torre inclinada. Pois não é que a torre desapareça, ou resulte abandonada: ela simplesmente tende a pender para um lado, seja para a direita, seja para a esquerda. E ela pendeu cada vez mais à esquerda, especialmente nos anos 30 .

Segundo a doxa progressista é impossível que a torre da cultura não penda para um lado ou para o outro das disputas sociais, não se incline para uma tendência política ou para a outra. Esse ponto de vista é, com certeza, o da cultura da torre inclinada. E poderíamos concordar que se trata, justamente, de um ganho de consciência política importante. Ora, a questão é se isso também supõe um ganho para a literatura, para a criação. E a questão dessa questão é se isso é importante, e por que é importante, ao lado do que é urgente na sociedade.

A literatura, em Woolf, sempre é assunto de visão, de busca de uma compreensão sensível, através da lembrança e da percepção. Para entender como afeta a situação da torre à criação literária é preciso se representar, mais uma vez, com o método compreensivo de Woolf, como é que a inclinação determina a visão que podia ter o escritor da vida humana. Em primeiro lugar, diz Woolf, a inclinação da torre traz simplesmente consciência de habitar em uma torre. Os escritores se tornaram conscientes, justamente, de não estar experimentando a vida humana como ela é, mas uma vida humana privilegiada, enquanto ao nascimento, à riqueza. Já não foi mais 
possível habitar a torre ignorando que era uma torre que se erguia sobre o solo comum. Essa consciência de privilégio provocou também uma transformação do olhar: não é que eles começaram a ver tudo às avessas, mas "de viés para um lado" (WOOLF, 2014, p. 443). Mas essa transformação também significou uma perda da capacidade de visão: “eles não olham para nenhuma classe no rosto" (WOOLF, 2014, p. 444). Daí a incapacidade de criar personagens, no sentido de indivíduos vivos como os que encontramos na realidade. Em lugar de indivíduos, na obra dos escritores da torre inclinada abundam os tipos sociais: burguês, almirante reformado, solteirona ou fabricante de armas, diz Woolf. Nesses tipos, que tem a função de bode expiatório, a literatura da torre inclinada maltrata a mesma sociedade que ao mesmo tempo lhe dá "uma boa vista e alguma espécie de segurança", e que não ousaria atacar diretamente, olhando no rosto. Daí à violência de suas críticas à sociedade burguesa, mas também, como diz Woolf, sua "frouxidão"; o caráter ao mesmo tempo destrutivo e vácuo dessa literatura. Olhando de viés e não de frente, atacando tipos sem aproximar indivíduos reais, se asseguram de chicotear "um cavalo morto ou quase morto, porque um cavalo vivo, se fosse açoitado, lhes daria um coice" (WOOLF, 2014, p. 451). Eles lutam contra fantasmas e em favor de outros fantasmas, o que resulta da turbação do olhar quando a torre se inclina.

"Para começar, um mal-estar; depois, autocomiseração por esse mal-estar, a qual logo se converte em raiva - raiva contra o construtor, contra a sociedade, por nos causar tal desconforto" (WOOLF, 2014, p. 444). Esses são os afetos básicos que resultam da inclinação da torre da aristocracia literária, e sua produção é um reflexo desse estado mental "cheio de discórdia e amargura, cheio de confusões e compromissos" (WOOLF, 2014, p. 446). Como vemos, Woolf não poupa as críticas à literatura "engajada". Para exemplificar essa crítica, ela analisa um poema de um escritor inglês hoje completamente esquecido, Louis MacNeice. Ora, essas análises podem ser perfeita e detalhadamente aplicadas à poesia de Brecht. Além da raiva contra a sociedade burguesa, da autocomiseração e da busca por bodes expiatórios, há mais dois elementos interessantes nessa análise, que não tem tanto a ver com a crítica da velha sociedade como com o anúncio da nova. O primeiro diz respeito ao didatismo, ao esforço de ensinar, de pregar a possibilidade e a necessidade de uma nova sociedade na qual todos os homens são livres e iguais. Eis a tarefa dessa literatura engajada (“Os poetas têm de 
ensinar; tem de pregar"), para a qual tudo vira tarefa, dever: "Tudo é um dever - até o amor." (WOOLF, 2014, p. 452).

Assim, o viés no olhar pode ser detectado tanto na crítica da velha sociedade, que só chicoteia, nos tipos sociais que funcionam como bode expiatório, cavalos mortos, quanto no apelo a uma nova sociedade, que permanece completamente no âmbito formal do dever. Daí que a poesia deles não seja tanto poesia de poeta como poesia de político, ou seja, oratória. Ela não nos fala na solidão, nem nos lembramos dela quando estamos sozinhos; quando a lemos e ouvimos estamos "num grupo, numa sala de aula" (WOOLF, 2014, p. 453). Eis uma poesia, portanto, que não chega a exprimir nada real da experiência humana, pois critica à sociedade real desde a posição de um dever ser que também não corresponde com alguma experiência real. E a efetividade didática de sua pregação é tão indeterminável como a das Peças didáticas de Brecht ${ }^{9}$, o que não deveria resultar tão surpreendente: pois como "pode um escritor que não tem nenhuma experiência de uma sociedade sem classes e sem torres criar uma sociedade assim?" (WOOLF, 2014, p. 452). Desse modo, a poesia é sacrificada à crítica frouxa, à oratória e à pregação, fiel reflexo de uma nova existência em que o poeta, que ainda assim não abandona sua torre, não consegue mais desenvolver nenhuma visão estável desde ela, sendo um "habitante de dois mundos, um à morte, o outro lutando para nascer" (WOOLF, 2014, p. 453).

\section{OS GRANDES EGOCÊNTRICOS E A SOCIEDADE SEM CLASSES E SEM TORRES}

É por isso interessante se perguntar, mais uma vez, o que é sombrio nos tempos sombrios, se os tempos mesmos ou nossa incapacidade de nos situar diante deles e produzir algum tipo de visão, de criação. A questão é decidir se as trevas estão na sociedade mesma, e então apenas uma grande mudança política espetacular e catastrófica poderia dissipá-las, ou se elas estão em nossos olhos, o que poderia ser transformado talvez com uma operação oftalmológica, com o aprendizado de outro

\footnotetext{
${ }^{9}$ Rancière tem analisado algumas das dificuldades do efeito de distanciação brechtiano, em seu ensaio sobre "Os paradoxos da arte política", pertencente ao livro $O$ espectador emancipado: "Pode contribuir para transformar o mapa do perceptível e do pensável, para criar novas formas de experiência sensível, novas distâncias em relação às configurações existentes do que é dado. Mas esse efeito não pode ser uma transmissão calculável entre choque artístico sensível, tomada de consciência intelectual e mobilização política." (RANCIÈRE, 2012, p. 66)

Revista do Instituto Histórico e Geográfico do Pará (IHGP), (ISSN: 2359-0831 - online), Belém, v. 04, n. 02, p. 102-124, jul./dez. 2017.
} 
ângulo de visão: com um trabalho de re-situação do escritor. Eis a dúvida que acrescenta Woolf à temática de Brecht: esses tempos sombrios não seriam talvez mais um bode expiatório? Mais uma justificativa para não descer da velha torre do privilégio, e ainda assim conservar certa boa consciência de estar cumprindo seu dever, já não mais como poeta, mas ao menos como cidadão? ${ }^{10} \mathrm{E}$ esse novo dever crítico-didático que define a existência do poeta nos tempos sombrios, não seria uma maneira de fugir de um dever mais autêntico próprio à poesia? Poderíamos dizer que o problema é que os poetas da torre inclinada, os poetas que abraçam a "tendência" revolucionária, nem fazem literatura nem fazem a revolução.

O escritor dos tempos sombrios, "engajado" ou político, ou mais em geral o escritor "moderno que está sentado numa torre inclinada", e que não vê nada realmente da vida humana, consegue enxergar ainda assim algo: a si mesmo. Eis o paradoxo que detecta Woolf com muita força: todos esses escritores tão sociais e políticos, tão preocupados com o destino coletivo da humanidade, na verdade são apenas criadores quando falam de si mesmos. E eles falam muito, mesmo: têm sido "grandes egocêntricos" (WOOLF, 2014, p. 455). Se não conseguiram nos dar grandes poemas, nem peças de teatro, nem romances, não é apenas porque sacrificaram a arte a seu engajamento social, mas, sobretudo, porque não conseguiram enxergar nada além de si mesmos. E isso é bem compreensível, mais uma vez, se seguimos Woolf e nos colocamos imaginariamente numa torre inclinada. Pois não conseguiam enxergar nada estável no mundo, e então não podiam trazer mais nada tampouco à lembrança, na escrita. Além disso, estavam sobressaturados de consciência: "consciência de si mesmos, consciência de classe, consciência das coisas em mudança, das coisas que ruíam..." (WOOLF, 2014, p. 454). E essa sobressaturação da consciência impede o trabalho próprio da literatura: "Não havia mais tranquilidade na qual eles pudessem relembrar. A mente esteve paralisada por dentro, por haver estado, na superfície, trabalhando sempre pesado" (WOOLF, 2014, p. 454).

Nessa existência da instabilidade das relações políticas e sociais e de constante trabalho da mente na superfície da consciência, a única experiência estável é a do próprio eu, e também o único tema que o poeta da torre inclinada abordou com coragem

\footnotetext{
${ }^{10}$ Aqui Woolf conecta com a imagem de Lukács sobre Adorno e a escola de Frankfurt, o "Grande Hotel Abismo" (LUKÁCS, 2000, p. 18).

Revista do Instituto Histórico e Geográfico do Pará (IHGP), (ISSN: 2359-0831 - online), Belém, v. 04, n. 02, p. 102-124, jul./dez. 2017.
} 
e sinceridade e, portanto, como um verdadeiro criador, contando as "verdades desagradáveis, não somente as lisonjeiras" (WOOLF, 2014, p. 455) ${ }^{11}$. É apenas em relação a si próprio que ele conseguiu atingir uma inconsciência, e portanto uma escrita que não levava em conta nenhuma convenção social, mas olhava à existência sem véus. Essa inconsciência e essa ausência de concessões enquanto à exposição e a autoanálise do eu é a grande contribuição dos escritores da torre inclinada à literatura: nisso e apenas nisso, eles vão mais longe do que os escritores da torre de estuque e ouro. Essa verdadeira riqueza da literatura engajada, que não é de caráter poético nem político mas autobiográfico, foi produto do único afeto com grandeza que lhes impulsou à escrita: o "desejo de ser completo; de ser humano".

"Tudo o que eu gostaria era de ser humano" é um grito que ecoa através de seus livros - é o anseio de estar mais perto da espécie, de escrever a fala comum da espécie, de compartilhar as emoções da espécie, não mais no isolamento e exaltação em situação solitária sobre a torre, e sim embaixo, de pés no chão, junto com a massa da espécie humana. (WOOLF, 2014, p. 454).

Assim, se os poetas dos tempos sombrios nos legaram alguma coisa, não é justamente o dever do engajamento ou o pathos da revolta, mas a aparição de um novo personagem, explorado bem mais além dos limites da convenção social. Paradoxalmente, certo aprofundamento na exploração do Eu, do indivíduo isolado, fora de qualquer representação, é a grande contribuição da literatura de tendência política. Em relação a essa busca de uma verdade completa do ser humano, os personagens tão vivos criados pela literatura da torre de estuco e ouro aparecem como bonecos, seres podados, divididos, cercados. Mesmo se os escritores modernos não conseguiram enxergar nada além da superfície das tendências sociais pela sua consciência hipertrofiada, eles conseguiram mergulhar na exploração inconsciente da vida humana neles mesmos. Eis o único deles que podemos lembrar na solidão: o aspecto autobiográfico da sua obra, o caráter puramente lírico, expressivo e subjetivo. É o único em que contribuíram à tradição da literatura, ou seja, à contemplação cada vez mais aprofundada da vida humana.

Há no egocentrismo desses escritores uma busca universal, uma busca da verdade da vida humana comum, não dividida nem parcelada em estamentos. Nisso, eles anteciparam a literatura de "um mundo sem classes e sem torres" (WOOLF, 2014,

\footnotetext{
${ }^{11}$ Eis o que liga o obra lírica de autores tão aparentemente dispares como Brecht e D.H. Lawrence, por exemplo.

Revista do Instituto Histórico e Geográfico do Pará (IHGP), (ISSN: 2359-0831 - online), Belém, v. 04, n. 02, p. 102-124, jul./dez. 2017.
} 
p. 457), que talvez poderia novamente olhar para o mundo em sua volta, criar personagens, viver de uma vida mais ampla do que a do Eu. Essa nova literatura, que já não seria mais a da torre de estuco e ouro (e da sociedade de estamentos), nem do período de transição da torre inclinada (e das guerras de classe), mas de uma verdadeira sociedade sem classes, deveria teoricamente ser melhor do que a anterior:

O romancista há de ter pessoas mais interessantes para descrever - pessoas que terão tido oportunidade de desenvolver seu humor, seus dons e gostos; pessoas reais, não pessoas comprimidas e esmagadas por cercas em massas sem feições definidas. Menos óbvio é o ganho do poeta, que esteve menos sujeitos ao domínio das cercas. Ele no entanto há de ganhar palavras; quando admitirmos todos os diferentes dialetos, o vocabulário mutilado e enclausurado que é hoje tudo o que ele usa há de sair enriquecido. (WOOLF, 2014, p. 459).

Ora, a condição desse ganho em palavras poéticas e em personagens de romance com maior riqueza humana é a estabilidade das relações sociais, e em geral da vida humana. Essa estabilidade é o que permite "olhar de frente" à vida humana, e devir inconsciente em relação às estruturas e mediações sociais. Mas para isso é necessário, como diz Woolf, algum tipo de crença comum, que tire dos ombros do escritor "o fardo da didática, da propaganda" (WOOLF, 2014, p. 459). Eis a verdade incômoda que se situa no coração da crítica de Woolf à suposta literatura engajada: que a fonte da criação não reside na revolta contra a ordem ou a consciência que se separa dele e o estranha, nem na esfera do dever que daí resulta, mas a submissão à ordem social, a inconsciência social ou política, a aceitação e o completo amor à vida humana como ela é. Apenas essa inconsciência consegue desenvolver o trabalho da criação: alçar o véu de maia das opiniões, das imagens da sociedade e das representações do mundo e mostrar a realidade humana como ela é, de uma maneira tranquila e serena, que fala às pessoas quando estão sozinhas, tranquilas e serenas, com uma comunicação de indivíduo humano a indivíduo humano, de solidão a solidão, que percorre a historia da humanidade e é sua verdadeira tradição. ${ }^{12}$

\footnotetext{
${ }^{12}$ Eis também a grande importância dos trabalhos de Rancière, que mostram que se existe uma política da literatura, ela não depende em nada das posições políticas conscientes do autor, mas de um trabalho próprio da literatura, e portanto inconsciente, de reconfiguração do campo de experiência sensível. Mas Woolf permite compreender muito bem por que os grandes revolucionários da literatura também têm sido muitas vezes conservadores nas suas posições políticas (só é preciso pensar em Flaubert), ou simplesmente apolíticos, e por que quando alguns grandes escritores, quando abandonam o conservadorismo ou o apolitismo e se lançam no didatismo e na propaganda, também perdem a força literária da escrita (Tolstoi). 
Essa inconsciência, no entanto, não é ignorância: é conhecimento e aceitação. E talvez nem seja sempre possível aceitar, para desgraça da literatura. Mas Woolf descreve uma hipotética situação em que o imposto da renda, ao invés do dilúvio capitalista do qual nascem os novos homens socialistas no poema de Brecht, traria paulatinamente consigo a sociedade sem classes. É significativo que ela não pense a mudança social como uma catástrofe, mas como um processo. Esse processo diz respeito fundamentalmente à educação. Com a pressão do imposto da renda, as mães de famílias abastadas não poderiam tão facilmente enviar seus filhos a escolas particulares caras, e teriam de enviá-los às escolas públicas, onde eles se misturariam com garotos de outras classes sociais, e desfrutariam então de uma experiência da humanidade mais rica que terminaria propiciando a dissolução das classes. Mas esse ganho em "mundo dos vivos" não poderia ser realizado a custas do "mundo dos mortos". Woolf comenta mais particularmente a carta que uma dessas mães escreveu a um jornal, onde é possível ler: "Quero para meu filho... o melhor dos dois mundos." (WOOLF, 2014, p. 459). Segundo a explicitação de Woolf: "O que ela queria em suma era a escola da aldeia, onde ele aprendia a se misturar com os vivos, e a outra escola - aquela situada em Winchester-, onde ele se misturava com os mortos" (WOOLF, 2014, p. 459).

Como podemos ver, a utopia woolfiana não é a de Brecht: a sociedade sem classes não é o novo mundo, o mundo do vivo que finalmente se desliga do que é morto. Se é possível que nasça uma vida humana sem classes, não seria na forma de uma nova humanidade social que renasceria da catástrofe do velho mundo capitalista, mas como um novo tipo de relações sociais que iriam se formar a partir da vida nas escolas públicas. Ora, para que isso acontecesse essas escolas públicas deveriam ter dois princípios diferentes, ligando o velho que está morrendo ao novo que ainda não nasceu. Em primeiro lugar, um princípio aristocrático enquanto ao tipo de educação, que seria o dessa formação indefinida dos escritores da torre de estuco e ouro. As escolas e universidades da sociedade sem classes deveriam ser espaços para os alunos "ler, ouvir, conversar, viajar, distrair-se": espaços, basicamente, de ociosidade, e de prática das virtudes da ociosidade. Mas em segundo lugar, haveria evidentemente um princípio democrático, enquanto ao acesso universal, à mistura ativa das classes.

A utopia educativa woolfiana é bem semelhante à que uma vez Antonio Machado fez enunciar a seu personagem Juan de Mairena, também sósias ou 
heterônimo: a escola popular de sabedoria superior (MACHADO, 1986, p. 272). Ora, o aspecto utópico não é o determinante nem o caráter principal do ensaio de Woolf. As "escolas populares de sabedoria superior", esse sonho de uma educação ao mesmo tempo aristocrática e plebeia, em que se misturam o mundo dos mortos e o mundo dos vivos, é uma simples projeção, como essa literatura da sociedade sem classes. E uma projeção não aproxima de outra, nem o sonho se transforma em realidade quando acrescentamos a um sonho mais outro sonho. O importante aqui não é o sonho da abolição tranquila da sociedade de classes através do imposto da renda e a reforma das escolas, que apenas é diferente na forma, e não no fundo, da grande catástrofe miraculosa brechtiana. Pois a questão em Woolf não é a de como sair finalmente da préhistória, mas a de como agir nela: como começar agora mesmo, como agir nos tempos sombrios. "Não precisamos esperar pelo fim da guerra. Podemos começar agora mesmo" (WOOLF, 2014, p. 462).

\section{O ESCRITOR PLEBEU}

Pois certamente ainda estamos na época tenebrosa das guerras de classe, e nossas escolas continuam mantendo o princípio aristocrático e o democrático cindidos, e o comum é que se pareçam mais a escolas superiores de sabedoria popular do que a escolas populares de sabedoria superior. Com certeza, também, ainda resulta muito complicado aceitar e amar a realidade como ela é sem ao mesmo tempo aceitar uma boa dose de cercas e de injustiça. Mas entre o poema de Brecht e o ensaio de Woolf, alguma coisa tem-se deslocado: é o sujeito mesmo da escrita. Pois a narradora ou a pensadora do ensaio de Woolf não é mais um escritor da torre inclinada, e por isso é capaz de tipificar escritores como Brecht. O sujeito em Woolf é uma figura não mais aristocrática, mas plebeia. Não é mais um herdeiro, só que com má consciência, de uma grande tradição; mas também não é aquele que não tem relação nenhuma com a tradição. A relação com a tradição daquele que podemos chamar já não mais de poeta dos tempos sombrios, ou de escritor da torre inclinada, mas de um inaudito intelectual plebeu, é uma relação de usurpação, de transgressão. Ele não escreve desde o alto de uma antiga torre feita de história e educação dispendiosa que aos poucos foi perdendo o equilíbrio. Ele também não escreve desde o chão mesmo, pois isso seria impossível: 
também escreve desde uma torre, só que essa torre é imaginária e construída por ele mesmo, e então pode em qualquer momento descer dela, não está preso à torre. "Podemos parar de imaginar. Podemos descer no chão." (WOOLF, 2014, p. 445).

O pathos do escritor plebeu também não é mais o da revolta. Isso é examinado no ensaio de Woolf ao redor dos sentimentos do escritor plebeu inglês em relação com sua própria língua e seu próprio pais. Com certeza, o afeto mais imediato que poderia conduzir o intelectual plebeu à escrivaninha seria o da revolta, quando ele pensa em como a Inglaterra tem produzido uma pequena e aristocrática tradição literária às custas de manter afastada de qualquer educação à maior parte da sua população. Mas essa revolta contra a tradição é um luxo dos herdeiros, dos que já tem uma tradição. O problema mais urgente do escritor plebeu é o de estabelecer uma relação com a tradição, ou de construir uma torre imaginaria desde a que poder olhar ao longe no tempo e no espaço, com essa tranquilidade que é a condição da criação.

A questão não é a de adotar uma atitude mais "construtiva" e menos "destrutiva", com a Inglaterra ou com os tempos sombrios. Pois o destrutivo é falsamente destrutivo, ainda mantem a velha relação com a tradição, ainda segura a herança e o capital. O problema do escritor plebeu, sua própria forma de ascese, é justamente a de resistir sua falsa identificação com os escritores da torre inclinada, e então resistir os primeiros impulsos que lhe conduzem à escrivaninha. Trata-se, no fundo, de resistir à tentação de adotar a posse do poeta dos tempos sombrios, que ainda é uma figura do herdeiro. A primeira questão que deve ser reconhecida pelo intelectual plebeu, para ter uma clara consciência de sua situação, é que ele não é mais um herdeiro "natural": a consciência de que a tradição plebeia apenas existe em uma relação de transgressão, de usurpação no que diz respeito à tradição "dominante", à tradição dos herdeiros da tradição.

Como escreve Woolf: “evitemos aderir, se nos for possível, à tribo amargurada e ineficaz dos caçadores de bodes expiatórios" (WOOLF, 2014, p. 460). Evitemos aderir, se nos for possível, e tal e como poderíamos traduzir, à tribo dos poetas "engajados", dos poetas da torre inclinada e dos tempos sombrios, dos poetas da grande catástrofe e da não menos espetacular salvação. Das cinzas do velho mundo não pode renascer um novo mundo, pois apenas há uma tradição: só que essa tradição não tem mais herdeiros naturais. Segundo certa temática de Rilke, os ricos já não são mais ricos, perderam sua 
tradição, a trocaram por dinheiro, por abstrações, viraram logo miseráveis com dinheiro. A única esperança, continuava esse poema de Rilke, é que os pobres continuem sendo pobres (RILKE, 2007). Pobres, quer dizer, não exatamente vivendo no chão, mas em torres imaginárias, construídas com palavras que são "roubadas" à tradição. Pobres no sentido em que as torres desde as quais escrevemos, e que nos elevam ao passado e à tradição, nunca vão ser completamente reais como as dos escritores aristocratas, nunca vão nos garantir que não podemos em qualquer momento cair; mas também têm a vantagem de nos permitir descer ao chão à vontade. Mas pobres também no sentido assumido, de "consciência de classe", de que não há como herdar sem transgredir, de que a tradição plebeia, essa coisa imaginária, apenas vive de usurpações.

Então, a situação do ensaio de Woolf, quando chama ao despertar e ao nascimento da consciência desses escritores plebeus, é a de uma tradição, a da literatura inglesa, que não pode mais ser transmitida naturalmente, ou herdada. Em lugar de uma "herança sem testamento" ou sem tradição, como na anotação de René Char que também virou temática filosófica em Hannah Arendt (ARENDT, 2014, p. 28), temos uma tradição sem herança, sem herdeiros naturais, que apenas é transmissível através de práticas de transgressão, de usurpação, e que só podem se praticadas pelos nãoherdeiros.

A transgressão não precisa adotar o sentimento da revolta, e é melhor que não a adote. Pois a construção dessa torre de tranquilidade e ociosidade que é a condição da literatura não é feita com tijolos de revolta, mas de aceitação. Ora, a aceitação mesma vira no ensaio de Woolf um ato de transgressão. Em lugar de usar "Inglaterra" como um bode expiatório para nossas insatisfações, podemos, diz Woolf, aceitar os livros que suas bibliotecas públicas nos oferecem.

Vejam só o que está escrito no livro que elas nos emprestou: "Pede-se aos leitores que comuniquem ao bibliotecário local quaisquer defeitos que eles possam notar". É a maneira de a Inglaterra dizer: "Se eu lhes empresto livros, espero que vocês se façam críticos." (WOOLF, 2014, p. 461).

Com certeza, não é isso o que a Inglaterra quis dizer, e a leitura de Woolf, consciente e ironicamente, desvia o sentido da frase. Ela faz falar à Inglaterra de um modo em que Inglaterra não fala, mais do que como personagem de ficção na literatura de Woolf. E com certeza essa Inglaterra que exige uma crítica e uma apropriação 
plebeias da sua própria tradição não existe fora da imaginação da escritora: não existe fora da literatura. O país que pede a seus cidadãos comuns, aos não herdeiros, que se apropriem da tradição, não existe. Esse país apenas pode existir, como no ensaio de Woolf, como um país literário, um país de ficção. A transgressão de Woolf consiste em fazer da Inglaterra não um bode expiatório para não escrever e fazer didática e oratória, mas um personagem da produção poética mesma. O intelectual plebeu não é aquele que escreve uma vez e outra que o tempo já não é mais o de escrever, mas o de agir, mas aquele para quem escrever é a forma mesma do agir: para quem escrever é uma questão de vida ou morte, o mais importante que se pode fazer ${ }^{13}$. Pois é a única maneira de transmitir uma tradição que já não tem herdeiros naturais, a tradição da vida humana.

Eis o conteúdo de verdade do ensaio de Woolf: uma crítica plebeia que não joga fora a tradição usando-a como bode expiatório, e na verdade a herdando como um "cavalo morto" ao que se chicoteia tranquilamente, mas que se apropria dela à maneira da transgressão. Essa crítica não apenas usurpa a voz da Inglaterra para fazer dela uma personagem de ficção, mas a dos grandes autores do passado:

Esquilo, Shakespeare, Virgílio e Dante [...], se pudessem falar - e afinal eles podem -, diriam: "Não me deixem para os embecados, os que usam perucas. Leiam-me, leiam-me vocês mesmos". Eles não ligam se cometemos erros de pronúncia ou se tivermos de ler com um roteiro ao lado. (WOOLF, 2014, P. 462).

Em lugar de chicotear o cadáver, trata-se de fazer reviver os mortos, de fazer falar os fantasmas, de lhes emprestar novas vozes. Mas novas vozes que também são as deles, pois "eles falam". Como Woolf escreve em outro ensaio, "aqui neste quarto, Keats, Shelley e Byron estão vivos em você e você e você" (WOOLF, 2014, p. 359). Ora, eles apenas falam e estão vivos na literatura, e na inconsciência da relação com o mundo do escritor que é a condição da literatura. Por isso é preciso fazer literatura e transmitir a literatura, mesmo se as bombas estão caindo do lado, e não há nada mais importante que se fazer. Eis a tarefa que Woolf coloca ao leitor comum: construir, mediante a crítica e a comparação perpetua da criação presente com a passada, a torre de uma cultura plebeia, feita de transgressões e de usurpações da tradição aristocrática.

\footnotetext{
13 "Provo isso agora, escrevendo a manhã inteira, quando poderia estar passeando, fazendo compras, ou aprendendo a fazer alguma coisa que será útil se a guerra vier. Sinto que, escrevendo, estou fazendo algo muito mais necessário do que qualquer outra coisa.” (WOOLF, 1986, p. 85) 
Desde esse ponto de vista, nosso presente, quando temos um presente, justamente coloca entre parênteses de inconsciência a visão turbada dos "tempos sombrios", para constituir um fragmento do mundo da emancipação plebeia. E o destino dessa emancipação é ligado por Woolf ao destino mesmo da literatura. Pois a literatura é esse país que "não é terreno de ninguém; a literatura é terreno de todos. Não foi retalhada em nações; lá não há guerras” (WOOLF, 2014, p. 463).

A tarefa do escritor nos tempos sombrios, podemos concluir, é a mesma que a do escritor em qualquer tempo, pois em geral todos os tempos foram sombrios. Trata-se, sempre, de atingir esse estado de tranquilidade e inconsciência, de ócio, que é o único capaz de retirar o véu de maia das representações da realidade para perceber a vida humana como ela é, e falar desde aí de solidão a solidão. Certamente, essa tarefa pode parecer mais pesada que a antiga, quando o peso da consciência das injustiças é tão forte como hoje, quando a experiência histórica é tão instável, quando a representação quer se apropriar de tudo e a discussão política afoga qualquer outro tipo de manifestação. Mas podemos decidir não fazer parte dos caçadores estéreis de bodes expiatórios. E podemos saber que essa situação não é tão nova, que é a típica dos escritores da torre inclinada. E podemos saber finalmente que não somos mais escritores da torre inclinada.

Ora, em grande parte, somos aquilo que os escritores da torre inclinada sonharam ser, e foram na sua literatura, nos seus melhores momentos: homens comuns, homens inteiros. Mas o homem inteiro já não é mais o herdeiro natural de nada: é um escritor sem herança, que apenas pode estabelecer uma relação com a tradição mediante usurpações. Ora, a usurpação da tradição, como tudo que diz respeito à literatura, apenas pode se desenvolver desde uma inconsciência radical. É nesse estado de inconsciência que o novo escritor plebeu pode transgredir livremente, que na voz dele podem falar outras vozes (Esquilo, Shakespeare, Virgílio ou Dante); e que o novo mundo que nasce, que apenas dispõe de um Eu mais real e profundo, mas ainda assim sem mundo, pode transmitir toda a riqueza da experiência histórica humana. Para isso o mais urgente é fazer o luto da figura do poeta dos tempos sombrios, e tudo o que ela implica. A força de Woolf, nesse sentido, que ainda nos fala plenamente hoje, ou que nos fala direta e urgentemente hoje, e ao mesmo tempo absolutamente a contramão, consiste tanto na sua crítica de certo progressismo literário muito habitual em nossos tempos, quanto na tarefa que coloca nos ombros dos não-herdeiros. Pois é a 
sobrevivência da inteira tradição literária inteira que depende doravante da emancipação dos plebeus.

\section{BIBLIOGRAFIA}

ARENDT, Hannah. Homens em tempos sombrios. Trad. Denise Bottmann. São Paulo: Companhia de Bolso, 2008.

ARENDT, Hannah. Entre o passado e o futuro. Trad. Mauro Barbosa de Almeida. São Paulo: Perspectiva, 2014.

BRECHT, Bertolt. Poemas 1913-1956. Trad. Paulo César de Souza. São Paulo: Editora 34, 2000.

BRECHT, Bertolt. Histórias do sr. Keuner. Trad. Paulo César de Souza. São Paulo: Editora 34, 2006.

DELEUZE, Gilles. Crítica e clínica. Trad. Peter Pál Pelbart. São Paulo: Editora 34, 1997.

LUKÁCS, Georg. A teoria do romance. Trad. José Marcos Mariani de Macedo. São Paulo: Editora 34, 2000.

MACHADO, Antonio. Juan de Mairena, I. Madrid: Cátedra, 1986.

RANCIÈRE, Jacques. O espectador emancipado. Trad. Ivonne C. Benedetti. São Paulo: Martins Fontes, 2012.

RILKE, Rainer Maria. O livro da pobreza e da morte. Trad. Ana Diogo e Rui Caeiro. Coimbra: Bonecos rebeldes, 2007.

WOOLF, Virginia. Momentos de vida. Trad. Paula Maria Rosas. Rio de Janeiro: Nova Fronteira, 1986.

WOOLF, Virginia. O valor do riso e outros ensaios. Trad. Leonardo Fróes. São Paulo: Cosac Naify, 2014. 